\title{
Methods for optical modeling and cross-checking in ellipsometry and scatterometry
}

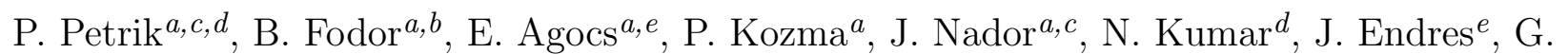

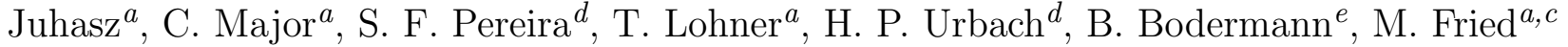 \\ ${ }^{a}$ Institute for Technical Physics and Materials Science, Centre for Energy Research, Hungarian \\ Academy of Sciences, Konkoly Thege Rd. 29-33, 1121 Budapest, Hungary \\ ${ }^{b}$ Doctoral School of Physics, Faculty of Science, University of Pécs, Ifjúság Str. 6, 7624 Pécs, \\ Hungary \\ ${ }^{c}$ Doctoral School of Molecular- and Nanotechnologies, Faculty of Information Technology, \\ University of Pannonia, Egyetem Str. 10, 8200 Veszprém, Hungary \\ ${ }^{d}$ Department of Imaging Physics, Faculty of Applied Sciences, Delft University of Technology, \\ P. O. Box 5046, 2600GA Delft, The Netherlands \\ ${ }^{e}$ Physikalisch-Technische Bundesanstalt, Bundesallee 100, 38116 Braunschweig, Germany
}

\begin{abstract}
Indirect optical methods like ellipsometry or scatterometry require an optical model to calculate the response of the system, and to fit the parameters in order to minimize the difference between the calculated and measured values. The most common problem of optical modeling is that the measured structures and materials turn out to be more complex in reality than the simplified optical models used as first attempts to fit the measurement. The complexity of the optical models can be increased by introducing additional parameters, if they (1) are physically relevant, (2) improve the fit quality, (3) don't correlate with other parameters. The sensitivity of the parameters can be determined by mathematical analysis, but the accuracy has to be validated by reference methods. In this work some modeling and verification aspects of ellipsometry and optical scatterometry will be discussed and shown for a range of materials (semiconductors, dielectrics, composite materials), structures (damage and porosity profiles, gratings and other photonic structures, surface roughness) and cross-checking methods (atomic force microscopy, electron microscopy, x-ray diffraction, ion beam analysis). The high-sensitivity, high-throughput, in situ or in line capabilities of the optical methods will be demonstrated by different applications.
\end{abstract}

Keywords: Ellipsometry, Scatterometry, Cross-checking, Comparative Study, Optical characterization, Thin films

\section{INTRODUCTION}

Thin film characterization methods are of primary importance in numerous key technologies like microelectronics, photovoltaics or sensorics. Vertical compositions can usually be determined by removing the films (e.g. by sputtering) during surface-sensitive measurements (such as secondary ion mass spectrometry, sputtered neutral mass spectrometry, X-ray photoelectron spectrometry, Auger electron spectrometry, glow-discharge optical emission spectrometry, glow-discharge mass spectrometry, Raman depth profiling), by non-destructive depth-profiling techniques (such as Rutherford backscattering spectrometry, elastic recoil detection analysis, angle-dependent soft X-ray emission spectroscopy, grazing incidence X-ray diffraction, ellipsometry), or by cross sectioning techniques (such as electron microscopy, scanning Auger electron microscopy, time-of-flight secondary ion mass spectrometry, Raman mapping). ${ }^{1}$ From the perspective of the above list and the features of thin film metrologies, the advantages of optical techniques like ellipsometry and scatterometry are three-fold. (1) They allow a quick measurement. Ellipsometry is typically capable of measuring a broad spectrum $(\approx 200-1700 \mathrm{~nm})$ within less than one second, whereas the other destructive (layer removal by sputtering) and cross-sectional methods require minutes or rather hours (e.g. in case of electron microscopy) for measuring in one point. (2) The second

Corresponding author: Peter Petrik, petrik@mfa.kfki.hu 
important feature is the sensitivity, especially in terms of vertical resolution, or geometrical parameters in case of scatterometry. Also, the lateral scale of characterization can vary from the diffraction limit (down to about one micron) to even meters. (3) Finally, the speed and sensitivity allows measurements on large surfaces ${ }^{2,3}$ and in situ or in line characterizations during thin film growth, ${ }^{4-6}$ processing ${ }^{7-14}$ and manufacturing. ${ }^{15,16}$

However, there is also a major challenge: the quantification is made through optical models and numerical methods, and therefore the interpretation of the results is not straightforward. ${ }^{17-19}$ Methods like the above mentioned complementary techniques, ${ }^{1}$ extended by scanning probe methods like atomic force microscopy (AFM) or scanning tunneling microscopy, are often used for cross-checking and verification. As shown below, these techniques also have drawbacks, such as different information depths. In this paper we show several results and point out some challenges, mainly focusing on our own results as examples.

\section{OPTICAL METHODS}

Some of the widely used optical surface and thin film characterization methods are reflectometry, ${ }^{20,21}$ ellipsometry $^{17-19}$ (polarimetry in general) and scatterometry. ${ }^{22}$ All these methods measure the change of electromagnetic radiation during reflection from or transmission through the investigated sample. The advantage of ellipsometry over reflectometry is that the input intensity does not have to be known, and the sensitivity is higher due to the capability of measuring the phase change between reflections polarized parallel and perpendicular to the plane of incidence. Ellipsometry can be considered as a special kind of interferometry, in which the reference beam is that of the orthogonal polarization. Scatterometry provides additional information if the sizes of characteristic surface features or structures are comparable or larger than the wavelength used for the characterization. A new possibility is the combination of the two methods, ${ }^{23}$ although ellipsometry has already been used for scattering or diffracting samples in specular or normal-incidence configurations. ${ }^{24-27}$ The high speed of optical methods can also be utilized in large area mapping of thin film properties, ${ }^{2,3,28}$ e.g. photovoltaic ${ }^{29}$ or display panels. Currently a 40-point spectroscopic line-scan can be made in $10 \mathrm{~s}$, and the near-future aim is a spectroscopic map of a $60 \mathrm{~cm}$ by $120 \mathrm{~cm}$ photovoltaic panel within 1 min. ${ }^{29}$

An emerging powerful method is Fourier scatterometry, which measures the light scattered from the focus of a large numerical aperture objective by imaging the Fourier plane. ${ }^{30,31}$ Consequently, the major advantage of the method is that a large range of scattering and azimuth angles (0-64 and 0-360 degrees for reflection and azimuth angles, respectively, with a numerical aperture of 0.9) can be measured quickly and simultaneously. A great challenge is currently the quick calculation based on the large number of acquired measurement data. Improved sensitivity has been demonstrated by utilizing a scanning focused spot, ${ }^{32-38}$ interferometry ${ }^{39,40}$ or ellipsometry. ${ }^{23}$

\section{MODELING}

Being indirect methods, optical techniques like reflectometry, scatterometry or ellipsometry require some a priori information on the investigated structure, which helps to build proper optical models. When investigating complex samples (e.g. involving special features like the line edge roughness, ${ }^{41}$ overlayer thickness and bottom rounding, ${ }^{42}$ vertical inhomogeneity ${ }^{43}$ or the parameterization of the dielectric function for spectroscopic measurements ${ }^{44}$ ) the number of fit parameters increases, and a reliable fit approaching the global minimum of the system can only be achieved by sophisticated procedures ${ }^{45}$ like the maximum likelihood method, ${ }^{46}$ random global search, ${ }^{47}$ simulated annealing or genetic algorithms. ${ }^{48}$

The sensitivity of the parameters can be checked by uncertainty analysis. ${ }^{23,32,49}$ In case of spectroscopy and characterization of material properties, the parameterization of the dielectric function is a major issue from which a lot of technologically important material properties can be obtained, like for the case of polycrystalline semiconductors. ${ }^{50,51}$ Also in scatterometry, using different wavelengths in a broad range can increase the accuracy, reliability and the number of fit parameters. ${ }^{52}$

For the modeling of structures, the most widely used approach is to think in terms of stratified systems composed of layers with plane and parallel boundaries, and to calculate the optical response using the transfer matrix method ${ }^{53}$ or (in case of diffracting samples) by the rigorous coupled wave analysis (RCWA). ${ }^{14,26,27,54,55}$ Finite element $(\mathrm{FEM})^{56,57}$ and finite difference in time domain (FDTD) methods $s^{58-60}$ are also rapidly emerging. 
In terms of materials, there is a wide range of parameterizations depending on the electron structure (mostly categorized as dielectrics, metals or semiconductors). ${ }^{61,62}$ Optical parameter reconstruction requires a lot of computation, therefore, grid computing (as applied in Ref. 63) or using graphics processing units ${ }^{64,65}$ are becoming more and more important.

\section{METHODS FOR CROSS-CHECKING}

Because of their indirect character, the validation of optical methods is of primary importance. It means that the method has to be traceable to a reference standard. ${ }^{66}$ Although a reference standard is a stable and highly reproducible structure ${ }^{67}$ it is suitable for validation only when measured and cross-checked with other reference methods. ${ }^{66}$ As a primary aim, it is also crucial to achieve accurate optical measurements at the industrial level. ${ }^{68}$

There are numerous thin film characterization techniques including depth profiling like secondary ion mass spectrometry, X-ray photoelectron spectrometry, Auger electron spectrometry, glow-discharge optical emission or mass spectrometry, Raman depth profiling, non-destructive techniques such as Rutherford backscattering spectrometry, heavy ion elastic recoil detection, angle-dependent soft X-ray emission spectroscopy, grazing incidence $\mathrm{X}$-ray diffraction or ellipsometry. Finally, there are the most traditional cross-sectioning techniques like scanning electron microscopy, scanning Auger electron microscopy, or Raman mapping. ${ }^{1}$ Table 2 of Ref. 1 gives a nice overview of the main characteristics of a large number of thin film profiling techniques. Most importantly, there were significant deviations observed between the different methods by measuring on the same structure, which also pointed out the importance of validation, and the significance of suitable reference and calibration structures and methods.

\section{PERIODIC SURFACE STRUCTURES}

The most frequently applied structures used for the validation of scatterometry are two-dimensional gratings evaluated by RCWA ${ }^{54,55}$ or $\mathrm{FEM}^{57}$ using goniometric scatterometry, ${ }^{52,69}$ Fourier scatterometry ${ }^{30-32}$ or ellipsometry. ${ }^{14,25-27}$ Most of these studies use scanning electron microscopy (SEM) and AFM for cross checking. However, the measurement of side-wall angles and corner roundings are challenging with both methods, for which only transmission electron microscopy (TEM) can be used as the most reliable reference method.

Measurement of height and side-wall angles are major weaknesses for SEM and AFM, respectively. Even with TEM, a possible lateral inhomogeneity remains a great problem (also for line edge roughness characterizations ${ }^{31}$ ), since the spot size of the optical measurements are usually much larger than the TEM image area. In Ref. 69, the deviation between the different SEM approaches was comparable with its deviation from the optical results. From top view SEM, a critical dimension deviation of approximately $3 \mathrm{~nm}$ was claimed with sophisticated signal analysis for line widths of $\approx 100 \mathrm{~nm}$. A typical agreement within several nanometers is obtained between the scatterometric and electron microscopic results ${ }^{37-39}$ (with accurate height values measured only by AFM) and also between different scatterometric approaches (Table 1), slightly depending on the methods for fitting and modeling, ${ }^{70}$ e.g. considering a possible unintentional surface overlayer. ${ }^{38,71}$

There is a large potential in the optical characterization of other two- or three-dimensional periodic structures from biological ${ }^{72}$ or bio-inspired ${ }^{73,74}$ to special fiber ${ }^{75}$ or sensor structures. ${ }^{76,77}$ In all these, the measurement on small areas (like single scales of butterfly wings ${ }^{78}$ ) or non-uniform surfaces is an important challenge, as well as the capability of the proper alignment of the sample surface. Efficient and powerful calculation methods ${ }^{53-55,57,60,79}$ with sophisticated algorithms ${ }^{45,46,48,63}$ are also becoming increasingly needed.

\section{SURFACE ROUGHNESS AND ULTRA-THIN LAYERS}

The high surface sensitivity of ellipsometry makes it especially suitable for roughness measurements for both surfaces $^{80}$ and interfaces ${ }^{81-83}$ on the nanometer scale. Besides other sophisticated methods like the RayleighRice theory ${ }^{84}$ the most popular and robust method for surface roughness measurement is the effective medium approximation (EMA). ${ }^{80,85-87}$ Although a good correlation was revealed between the root mean square roughness measured by AFM and the thickness of the roughness layer measured by ellipsometry using the EMA, some effects like the window size in AFM have to be taken into account for a proper comparison and quantification (Fig. 1). 
Table 1. Best-fit reconstruction of Si gratings using deep ultraviolet (DUV) scatterometry and Fourier scatterometry, utilizing the maximum likelihood estimation (MLE) and the non-linear least squares fit. The parameters of the grating are listed in the first column. [Reprinted from the SPIE Proceedings 9132 (2014) 913208-1, Endres et al., "Measurement comparison of goniometric scatterometry and coherent Fourier scatterometry".]

\begin{tabular}{|c|c|c|c|}
\hline \multirow{2}{*}{$\begin{array}{l}\text { Reconstruction } \\
\text { parameter }\end{array}$} & \multicolumn{2}{|c|}{ DUV scatterometer } & \multirow{2}{*}{\begin{tabular}{|c|}
$\begin{array}{c}\text { Fourier } \\
\text { scatterometer }\end{array}$ \\
$\begin{array}{c}\text { Nonlinear least } \\
\text { squares }\end{array}$
\end{tabular}} \\
\hline & MLE & $\begin{array}{c}\text { Nonlinear least } \\
\text { squares }\end{array}$ & \\
\hline Middle CD [nm] & $301.5 \pm 1.5$ & $277.5 \pm 1.2$ & 277.0 \\
\hline Height [nm] & $361.0 \pm 1.0$ & $370.8 \pm 0.5$ & 365.0 \\
\hline Side wall angle $\left[{ }^{\circ}\right]$ & $83.8 \pm 0.3$ & $81.9 \pm 0.2$ & 90.0 \\
\hline $\begin{array}{l}\text { Oxide layer } \\
\text { thickness }[\mathrm{nm}]\end{array}$ & $4.9 \pm 0.5$ & $2.77 \pm 0.28$ & 5.0 \\
\hline Bias value $[\mathrm{nm}]$ & & & 150 \\
\hline
\end{tabular}

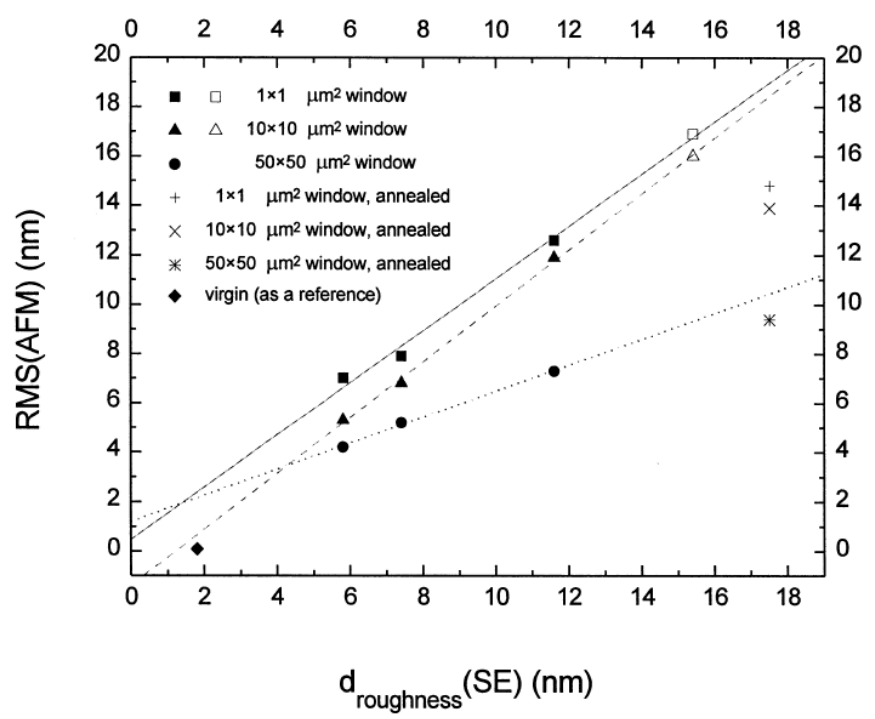

Figure 1. Root mean square (RMS) roughness measured by atomic force microscopy (AFM) correlated with the roughness determined by spectroscopic ellipsometry (SE), for different AFM window sizes. ${ }^{87}$ [Reprinted from Thin Solid Films 315 (1998) 186, Petrik et al., "Surface roughness measurement on polysilicon produced by low pressure chemical vapor deposition using spectroscopic ellipsometry and atomic force microscopy". Copyright 1998, with permission from Elsevier.] 


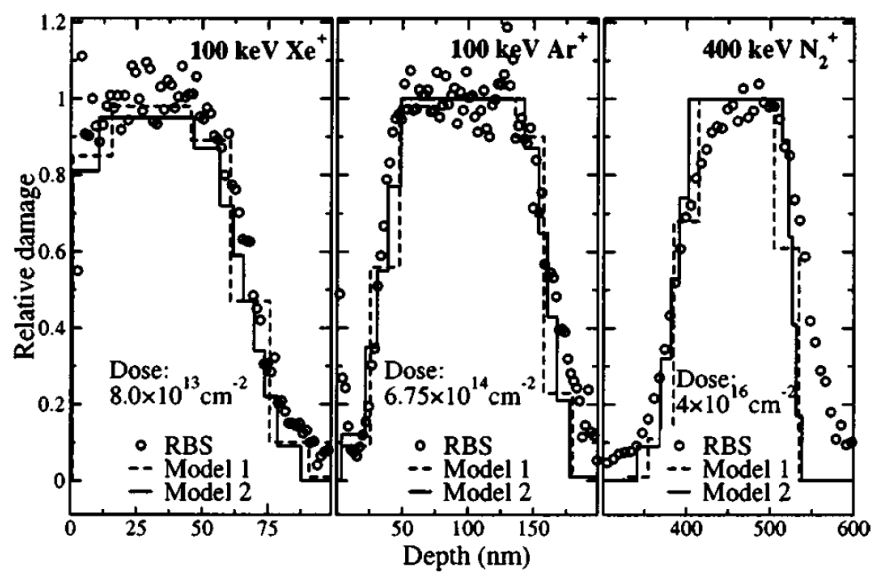

Figure 2. Damage depth profiles in Si, induced by implantation of $\mathrm{Xe}^{+}, \mathrm{Ar}^{+}$and $\mathrm{N}_{2}^{+}$ions at different energies (see graphs) measured by spectroscopic ellipsometry (lines) verified by Rutherford backscattering spectrometry (RBS). The optical models were based on coupled half-Gaussians ${ }^{97,98}$ with equal sublayer thicknesses (Model 1) or sublayer thicknesses inversely proportional to the slope of the profile (Model $2,{ }^{92}$ ). Reprinted from the Journal of Applied Physics 93 (2003) 1987, Petrik et al., "Ellipsometric characterization of damage profiles using an advanced optical model".

In case of ultra-thin (several nanometers) layers the interface roughnesses ${ }^{82,83}$ and the surface contamination are crucial questions. It was shown that native oxide covered samples acquire 0.1 to $0.2 \mathrm{~nm}$ of organic contamination within two hours stored in closed but nonvacuum conditions. Subsequently, another 0.2 to $0.5 \mathrm{~nm}$ layer is deposited, which is saturated in approximately in one week. ${ }^{88}$ The thickness in that study was a kind of ' $\mathrm{SiO}_{2}$-equivalent' thickness - the accurate analytical measurement of low surface contamination is also very challenging. ${ }^{89}$ The above contamination layer is the reason why ellipsometry usually slightly overestimates the thicknesses of ultra-thin layers when compared with methods measuring in vacuum (see the comprehensive study involving ion beam, X-ray, electron and optical investigations in Ref. 90).

\section{DEPTH PROFILING IN SEMICONDUCTORS}

For optical techniques accessing higher photon energies (e.g. the direct interband transition energies of 3.4 and $4.2 \mathrm{eV}$ in $\mathrm{Si}$ ), the long range order and minute changes in the crystal lattice can be measured with high sensitivity. This is the reason why ellipsometry can be applied for the measurement of polycrystalline and ion implanted semiconductors. Damage profiles can be determined from the optical measurements using multilayer models with the EMA and the transfer matrix method. Besides TEM, an accurate verification method for damage profile measurement is the ion beam analysis (when the sample is single-crystalline or the grains of the polycrystal are not randomly oriented ${ }^{91}$ ) irradiated from channeling directions. Fig. 2 demonstrates the agreement in damage profiles measured by ellipsometry and Rutherford backscattering spectrometry (RBS). ${ }^{92}$ In case of very thin layers, medium energy ion scattering is even more accurate than RBS. ${ }^{93,94}$ The combination of RBS with ellipsometry is also a powerful method for density measurements, because ellipsometry provides an accurate thickness value, whereas RBS delivers the number of atoms per unit surface. ${ }^{95}$

In case of near surface cavities in $\mathrm{Si}$, the high sensitivity is ensured by the large optical contrast between void and Si. In this case, TEM is the most suitable verification method. We have obtained good agreements in different studies. ${ }^{63,96}$

Finally, it should be pointed out that the decreased penetration depth at direct interband transition photon energies is not only a problem, but it can also be utilized for depth scanning, when properly choosing the wavelength range used for the optical characterization (Fig. 3). By a systematic scan of the wavelength range, the penetration depth can be varied in a controlled way, which allows a model-independent direct depth scan. This might open new directions in the optical characterization of vertically non-uniform absorbing films. ${ }^{99}$ 


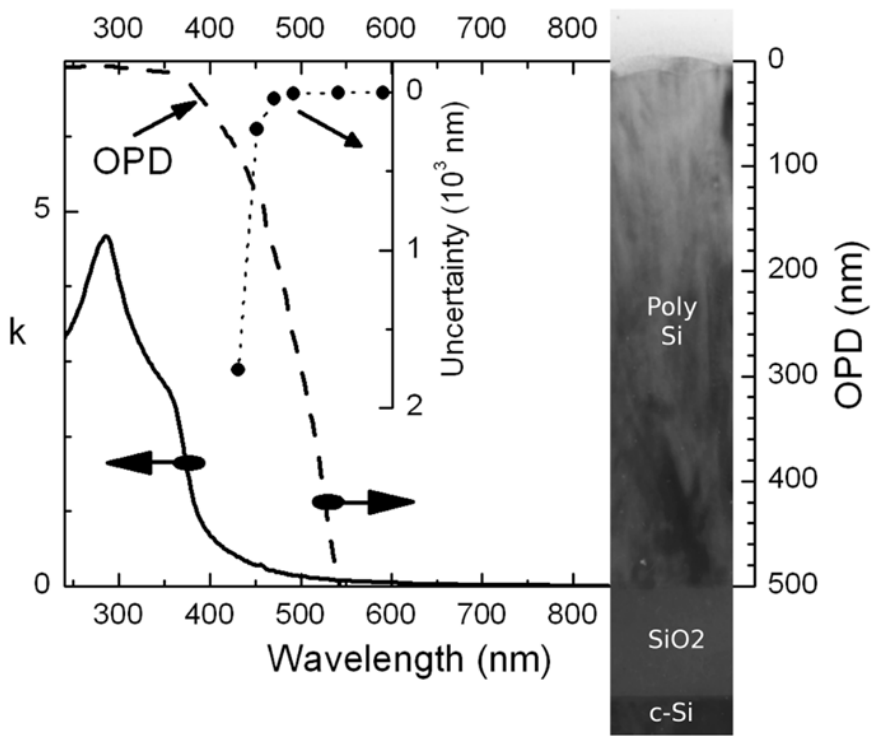

Figure 3. Extinction coefficient (k) and optical penetration depth (OPD) of a polycrystalline silicon layer (see TEM image on the right-hand side) as a function of the wavelength. The uncertainty of the fitted thickness is also shown as a function of the cut-off wavelength.

\section{CONCLUSIONS}

We have shown some aspects of optical modeling and cross-checking in ellipsometry and scatterometry. Proper quantification and the need for reference samples remain major challenges in the future, not only for optical but also for most other metrologies. ${ }^{1,89,90}$

\section{ACKNOWLEDGMENTS}

Support from ENIAC E450EDL, KMR_12_1_2012_0225, EMRP IND17 joint research project on scatterometry and from OTKA grant K81842 are greatly acknowledged. The EMRP is jointly funded by the EMRP participating countries within EURAMET and the European Union.

\section{REFERENCES}

1. Abou-Ras, D., Caballero, R., Fischer, C.-H., Kaufmann, C. A., Lauermann, I., Mainz, R., Mönig, H., Schöpke, A., Stephan, C., Streeck, C., Schorr, S., Eicke, A., Döbeli, M., Gade, B., Hinrichs, J., Nunney, T., Dijkstra, H., Hoffmann, V., Klemm, D., Efimova, V., Bergmaier, A., Dollinger, G., Wirth, T., Unger, W., Rockett, A. A., Perez-Rodriguez, A., Alvarez-Garcia, J., Izquierdo-Roca, V., Schmid, T., Choi, P.-P., Müller, M., Bertram, F., Christen, J., Khatri, H., Collins, R. W., Marsillac, S., and Kötschau, I., "Comprehensive comparison of various techniques for the analysis of elemental distributions in thin films," Microscopy and Microanalysis 17, 728 (2011).

2. Juhasz, G., Horvath, Z., Major, C., Petrik, P., Polgar, O., and Fried, M., "Non-collimated beam ellipsometry," Physica Status Solidi C 5, 1081 (2008).

3. Fried, M., Juhasz, G., Major, C., Petrik, P., Polgar, O., Horvath, Z., and Nutsch, A., "Expanded beam (macro-imaging) ellipsometry," Thin Solid Films 519, 2730 (2011).

4. Kurunczi, S., Nemeth, A., Hulber, T., Kozma, P., Petrik, P., Jankovics, H., Sebestyen, A., Vonderviszt, F., Fried, M., and Barsony, I., "In situ ellipsometric study of surface immobilization of flagellar filaments," Appl. Surf. Sci. 257, 319 (2010).

5. Nemeth, A., Kozma, P., Hulber, T., Kurunczi, S., Horvath, R., Petrik, P., Muskotal, A., Vonderviszt, F., Hős, C., Fried, M., Gyulai, J., and Barsony, I., "In situ spectroscopic ellipsometry study of protein immobilization on different substrates using liquid cells," Sensor Letters 8, 1 (2010). 
6. Kozma, P., Kozma, D., Nemeth, A., Jankovics, H., Kurunczi, S., Horvath, R., Vonderviszt, F., Fried, M., and Petrik, P., "In-depth characterization and computational 3d reconstruction of flagellar filament protein layer structure based on in situ spectroscopic ellipsometry measurements," Appl. Surf. Sci. 257, 7160 (2011).

7. Collins, R. W. and Yang, B. Y., "In situ ellipsometry of thin-film deposition: Implications for amorphous and microcrystalline si growth," J. Vac. Sci. Technol. B7, 1155 (1989).

8. Vuye, G., Fisson, S., Van, V. N., Wang, Y., Rivory, J., and Abelès, F., "Temperature dependence of the dielectric function of silicon using in situ spectroscopic ellipsometry," Thin Solid Films 233, 166 (1993).

9. Tachibana, K., Shirafuji, T., Hayashi, Y., and Maekawa, S., "In situ ellipsometric monitoring of the growth of polycrystalline silicon thin films by rf plasma chemical vapor deposition," Japanese Journal of Applied Physics 33, 4191 (1994).

10. Lehnert, W., Berger, R., Schneider, C., Pfitzner, L., Ryssel, H., Stehle, J. L., Piel, J.-P., and Neumann, W., "In situ spectroscopic ellipsometry for advanced process control in vertical furnaces," Thin Solid Films 313314, 442 (1998).

11. P. R. Lefebvre, Zhao, C., and E. A. Irene, "An in situ and ex situ ellipsometry comparison of the interfaces of si and gaas resulting from thermal and plasma oxidation," Thin Solid Films 313-314, 454 (1998).

12. Maynard, H. L., Layadi, N., and Lee, J. T. C., "Plasma etching of submicron devices: in situ monitoring and control by multi-wavelength ellipsometry," Thin Solid Films 313-314, 398 (1998).

13. Petrik, P., Lehnert, W., Schneider, C., Fried, M., Lohner, T., Gyulai, J., and Ryssel, H., "In situ spectroscopic ellipsometry for the characterization of polysilicon formation inside a vertical furnace," Thin Solid Films 364, 150 (2000).

14. Huang, H.-T. and Terry Jr, F. L., "Erratum to Spectroscopic ellipsometry and reflectometry from gratings (Scatterometry) for critical dimension measurement and in situ, real-time process monitoring [Thin Solid Films 455456 (2004) 828836]," Thin Solid Films 468, 339-346 (Dec. 2004).

15. Piel, J.-P., Stehle, J.-L., and Thomas, O., "The fastest real time spectroscopic ellipsometry: Applications and limitations for in situ and quality control," Thin Solid Films 233, 301 (1993).

16. Schneider, C., Berger, R., Pfitzner, L., and Ryssel, H., "In situ ellipsometry for real-time feedback control of oxidation furnaces," Appl. Surf. Sci. 63, 135 (1993).

17. Tompkins, H. G. and Irene, E. A., [Handbook Of Ellipsometry], William Andrew (2005).

18. Fujiwara, H., [Spectroscopic Ellipsometry: Principles and Applications], Wiley, New York (2007).

19. Losurdo, M. and Hingerl, K., [Ellipsometry at the Nanoscale], Springer-Verlag, Heidelberg (2012).

20. Gumprecht, T., Petrik, P., Roeder, G., Schellenberger, M., Pfitzner, L., and Pollakowski, B., "Characterization of Thin ZnO Films by Vacuum Ultra-Violet Reflectometry," 1494 (2012).

21. Nečas, D., Čudek, V., Vodák, J., Ohlídal, M., Klapetek, P., Benedikt, J., Rügner, K., and Zajíčková, L., "Mapping of properties of thin plasma jet films using imaging spectroscopic reflectometry," Measurement Science and Technology 25, 115201 (Nov. 2014).

22. Bodermann, B., Buhr, E., Danzebrink, H.-U., Bär, M., Scholze, F., Krumrey, M., Wurm, M., Klapetek, P., Hansen, P.-E., Korpelainen, V., van Veghel, M., Yacoot, A., Siitonen, S., O. El Gawhary, Burger, S., and Saastamoinen, T., "Joint research on scatterometry and AFM wafer metrology," AIP Conference Proceedings 1395, 319 (2011).

23. Petrik, P., Kumar, N., Fried, M., Fodor, B., Juhasz, G., Pereira, S. F., Burger, S., and Urbach, H. P., "Fourier ellipsometry - an ellipsometric approach to Fourier scatterometry," Journal of the European Optical Society: Rapid Publications 10, 15002 (Jan. 2015).

24. Niu, X., Jakatdar, N., Bao, J., Spanos, C., and Yedur, S., "Specular spectroscopic scatterometry in DUV lithography," Proceedings of SPIE - The International Society for Optical Engineering 3677(I), 159-168 (1999).

25. Huang, H.-T., Kong, W., and Terry, F. L., "Normal-incidence spectroscopic ellipsometry for critical dimension monitoring," Applied Physics Letters 78, 3983 (2001).

26. Antos, R., Pistora, J., Ohlidal, I., Postava, K., Mistrik, J., Yamaguchi, T., Visnovsky, S., and Horie, M., "Specular spectroscopic ellipsometry for the critical dimension monitoring of gratings fabricated on a thick transparent plate," Journal of Applied Physics 97(5), 053107 (2005). 
27. Antos, R., Pistora, J., Mistrik, J., Yamaguchi, T., Yamaguchi, S., Horie, M., Visnovsky, S., and Otani, Y., "Convergence properties of critical dimension measurements by spectroscopic ellipsometry on gratings made of various materials," Journal of Applied Physics 100(5), 054906 (2006).

28. Fried, M., Juhasz, G., Major, C., Nemeth, A., Petrik, P., Polgar, O., Salupo, C., Dahal, L. R., and Collins, R. W., "Application of a Dual-spectral-range, Divergent-beam Spectroscopic Ellipsometer for HighSpeed Mapping of Large-area, Laterally-inhomogeneous, Photovoltaic Multilayers," MRS Proceedings 1323, mrss11-1323-c03-12 (June 2011).

29. Fried, M., "On-line monitoring of solar cell module production by ellipsometry technique," Thin Solid Films 571, 345-355 (Nov. 2014).

30. Boher, P., Luet, M., Leroux, T., Petit, J., Barritault, P., Hazart, J., and Chaton, P., "Innovative rapid photo-goniometry method for CD metrology," SPIE Proceedings 5375, 1302 (2004).

31. Boher, P., Petit, J., Foucher, J., Desieres, Y., Hazart, J., and Chaton, P., "Optical Fourier transform scatterometry for LER and LWR metrology," SPIE Proceedings 5752, 192 (2005).

32. El Gawhary, O., Kumar, N., Pereira, S. F., Coene, W. M. J., and Urbach, H. P., "Performance analysis of coherent optical scatterometry," Applied Physics B 105, 775 (2011).

33. Roy, S., El Gawhary, O., Kumar, N., Pereira, S. F., and Urbach, H. P., "Scanning effects in coherent fourier scatterometry," Journal of the European Optical Society - Rapid Publications 7, 12031 (2012).

34. Kumar, N., El Gawhary, O., Roy, S., Kutchoukov, V. G., Pereira, S. F., Coene, W., and Urbach, H. P., "Coherent Fourier scatterometry (tool for improved sensitivity in semiconductor metrology)," SPIE Proceedings 8324, 83240Q (2012).

35. Kumar, N., El Gawhary, O., Roy, S., Pereira, S. F., and Urbach, H. P., "Phase information in coherent Fourier scatterometry," SPIE Proceedings 8788, 87881P (2013).

36. Kumar, N., El Gawhary, O., Roy, S., Pereira, S. F., and Urbach, H. P., "Phase retrieval between overlapping orders in coherent Fourier scatterometry using scanning," Journal of the European Optical Society - Rapid Publications 8, 13048 (2013).

37. Kumar, N., Petrik, P., Ramanandan, G. K. P., El Gawhary, O., Roy, S., Pereira, S. F., Coene, W. M. J., and Urbach, H. P., "Reconstruction of sub-wavelength features and nano-positioning of gratings using coherent Fourier scatterometry.," Optics express 22, 24678-88 (Oct. 2014).

38. Kumar, N., Coherent Fourier Scatterometry, PhD thesis, Delft University of Technology (2015).

39. Paz, V. F., Peterhänsel, S., Frenner, K., and Osten, W., "Solving the inverse grating problem by white light interference fourier scatterometry," Nature Light: Science and Applications 1, e36 (2012).

40. Roy, S., Kumar, N., Pereira, S. F., and Urbach, H. P., "Interferometric coherent fourier scatterometry: a method for obtaining high sensitivity in the optical inverse-grating problem," Journal of Optics 15, 075707 (2013).

41. Gross, H., Henn, M.-A., Heidenreich, S., Rathsfeld, A., and Bär, M., "Modeling of line roughness and its impact on the diffraction intensities and the reconstructed critical dimensions in scatterometry," Applied Optics 51, 7384 (Oct. 2012).

42. Endres, J., Diener, A., Wurm, M., and Bodermann, B., "Investigations of the influence of common approximations in scatterometry for dimensional nanometrology," Measurement Science and Technology 25, 044004 (Apr. 2014).

43. Petrik, P., "Ellipsometric models for vertically inhomogeneous composite structures," Physica Status Solidi A 205, 732 (2008).

44. Basa, P., Petrik, P., Fried, M., Dobos, L., Pécz, B., and Tóth, L., "Si nanocrystals in silicon nitride: An ellipsometric study using parametric semiconductor models," Physica E 38, 76 (2007).

45. Polgar, O., Petrik, P., Lohner, T., and Fried, M., "Evaluation strategies for multi-layer, multi-material ellipsometric measurements," Applied Surface Science 253, 57 (2006).

46. Henn, M.-A., Gross, H., Scholze, F., Wurm, M., Elster, C., and Bär, M., "A maximum likelihood approach to the inverse problem of scatterometry.," Optics Express 20(12), 12771-86 (2012).

47. Petrik, P., Cayrel, F., Fried, M., Lohner, T., Polgár, O., Gyulai, J., and Alquier, D., "Optical models for cavity profiles in high-dose helium-implanted and annealed silicon measured by ellipsometry," J. Appl. Phys 97, 123514 (2005). 
48. Polgár, O., Fried, M., Lohner, T., and Bársony, I., "Comparison of algorithms used for evaluation of ellipsometric measurements random search, genetic algorithms, simulated annealing and hill climbing graphsearches," Surface Science 457, 157-177 (June 2000).

49. Germer, T. A., Patrick, H. J., Silver, R. M., and Bunday, B., "ititle¿Developing an uncertainty analysis for optical scatterometryi/title,," in [Proceedings of SPIE - The International Society for Optical Engineering], Allgair, J. A. and Raymond, C. J., eds., 7272, 72720T-72720T-11 (Mar. 2009).

50. Petrik, P. and Fried, M., "Ellipsometry of semiconductor nanocrystals," in [Ellipsometry at the Nanoscale], Losurdo, M. and Hingerl, K., eds., Springer-Verlag, Heidelberg (2012).

51. Petrik, P., "Characterization of nanocrystals using spectroscopic ellipsometry," in [Nanocrystals - Synthesis, Characterization and Applications], Neralla, S., ed., InTech (2012). DOI: 10.5772/48732, ISBN: 978-953-51-0714-9, http://www.intechopen.com/books/nanocrystals-synthesis-characterization-andapplications/characterization-of-nanocrystals-using-spectroscopic-ellipsometry.

52. Scholze, F., Bodermann, B., Burger, S., Endres, J., Haase, A., Krumrey, M., Laubis, C., Soltwisch, V., Ullrich, A., and Wernecke, J., "Determination of line profiles on photomasks using DUV, EUV, and x-ray scattering," in [Proceedings of SPIE - The International Society for Optical Engineering], Behringer, U. F. W., ed., 9231, 92310M, SPIE (Oct. 2014).

53. Azzam, R. M. A. and Bashara, N. M., [Ellipsometry and Polarized Light], Elsevier (1987).

54. Moharam, M. G., Pommet, D. A., and Grann, E. B., "Stable implementation of the rigorous coupled-wave analysis for surface-relief gratings: enhanced transmittance matrix approach," Journal of the Optical Society of America 12, 1077 (1995).

55. van Kraaij, M. G. M. M., Forward Diffraction Modelling: Analysis and Application to Grating Reconstruction, PhD thesis, Technische Universiteit Eindhoven (2011).

56. Burger, S., Köhle, R., Zschiedrich, L., Gao, W., Schmidt, F., März, R., and Nölscher, C., "Benchmark of FEM, waveguide and FDTD algorithms for rigorous mask simulation," in [Proceedings of SPIE - The International Society for Optical Engineering], Weed, J. T. and Martin, P. M., eds., 5992, 599216-599216-12 (Oct. 2005).

57. Burger, S., Zschiedrich, L., Pomplun, J., Schmidt, F., and Bodermann, B., "Fast simulation method for parameter reconstruction in optical metrology," Proc. SPIE 8681, Metrology, Inspection, and Process Control for Microlithography XXVII 8681, 868119 (2013).

58. Cheung, K. T., Foo, Y., To, C. H., and Zapien, J. A., "Towards FDTD modeling of spectroscopic ellipsometry data at large angles of incidence," Applied Surface Science 281, 2-7 (Sept. 2013).

59. Foo, Y., Cheung, K. T., To, C. H., and Zapien, J. A., "On the modeling of ellipsometry data at large angles of incidence using finite-difference time-domain," Thin Solid Films 571, 669-674 (Nov. 2014).

60. P. Klapetek and M. Valtr, gsvit FDTD solver. http://www.gsvit.net (2015).

61. Fried, M., Lohner, T., and Petrik, P., "Ellipsometric characterization of thin films," in [Handbook of Surfaces and Interfaces of materials: "Solid Thin Films and Layers"], Nalwa, H. S., ed., Academic Press, San Diego (2001).

62. Collins, R. W. and Ferlauto, A. S., "Optical physics of materials," in [Handbook of ellipsometry], Irene, E. G. and Tomkins, H. G., eds., William Andrew, Norwich, NY (2005).

63. Petrik, P., Fried, M., Vazsonyi, E., Basa, P., Lohner, T., Kozma, P., and Makkai, Z., "Nanocrystal characterization by ellipsometry in porous silicon using model dielectric function," Journal of Applied Physics 105, 024908 (2009).

64. Klapetek, P. and Valtr, M., "Near-field optical microscopy simulations using graphics processing units," Surface and Interface Analysis 42, 1109-1113 (Apr. 2010).

65. Klapetek, P., Valtr, M., Poruba, A., Nečas, D., and Ohlídal, M., "Rough surface scattering simulations using graphics cards," Applied Surface Science 256, 5640-5643 (July 2010).

66. Bodermann, B., Loechel, B., Scholze, F., Dai, G., Wernecke, J., Endres, J., Probst, J., Schoengen, M., Krumrey, M., Hansen, P.-E., and Soltwisch, V., "Development of a scatterometry reference standard," in [Proceedings of SPIE - The International Society for Optical Engineering], Gorecki, C., Asundi, A. K., and Osten, W., eds., 9132, 91320A, SPIE (May 2014). 
67. Bodermann, B., Hansen, P.-E., Burger, S., Henn, M.-A., Gross, H., Bär, M., Scholze, F., Endres, J., and Wurm, M., "First steps towards a scatterometry reference standard," SPIE Proceedings 8466, 84660E-1 (2012).

68. Bodermann, B., Köning, R., Bergmann, D., Häß ler Grohne, W., Flügge, J., and Bosse, H., [Road towards accurate optical width measurements at the industrial level], Springer Berlin Heidelberg, Berlin, Heidelberg (2014).

69. Raymond, C. J., Murnane, M. R., Prins, S. L., Sohail, S., Naqvi, H., McNeil, J. R., and Hosch, J. W., "Multiparameter grating metrology using optical scatterometry," Journal of Vacuum Science and Technology B: Microelectronics and Nanometer Structures 15(2), 361-368 (1997).

70. Endres, J., Kumar, N., Petrik, P., M.-A. Henn, Heidenreich, S., Pereira, S. F., Urbach, H. P., and Bodermann, B., "Measurement comparison of goniometric scatterometry and coherent fourier scatterometry," SPIE Proceedings 9132, 913208-1 (2014).

71. Kumar, N., Petrik, P., Pereira, S. F., and Urbach, P., "Reconstruction of unintentional surface over-layer thickness on si-etched gratings," to be published.

72. Arwin, H., Magnusson, R., Garcia-Caurel, E., Fallet, C., Järrendahl, K., Foldyna, M., De Martino, A., and Ossikovski, R., "Sum decomposition of Mueller-matrix images and spectra of beetle cuticles," Optics Express 23(3), 1951-1966 (2015).

73. Biró, L. and Vigneron, J., "Photonic nanoarchitectures in butterflies and beetles: valuable sources for bioinspiration," Laser \& Photonics Reviews 5, 27-51 (Jan. 2011).

74. Tamáska, I., Vértesy, Z., Deák, A., Petrik, P., Kertész, K., and Biró, L. P., "Optical properties of bioinspired disordered photonic nanoarchitectures," Nanopages 8, 17 (2013).

75. Hansen, P.-E. and Burger, S., "Investigation of microstructured fiber geometries by scatterometry," in [Proceedings of SPIE - The International Society for Optical Engineering], Bodermann, B., Frenner, K., and Silver, R. M., eds., 8789, 87890R (May 2013).

76. Kertész, K., Piszter, G., Jakab, E., Bálint, Z., Vértesy, Z., and Biró, L. P., "Temperature and saturation dependence in the vapor sensing of butterfly wing scales.," Materials science $\mathcal{E}$ engineering. C, Materials for biological applications 39, 221-6 (June 2014).

77. Piszter, G., Kertész, K., Vértesy, Z., Bálint, Z., and Biró, L. P., "Substance specific chemical sensing with pristine and modified photonic nanoarchitectures occurring in blue butterfly wing scales.," Optics express 22, 22649-60 (Sept. 2014).

78. Kertész, K., Molnár, G., Vértesy, Z., Koós, A., Horváth, Z., Márk, G., Tapasztó, L., Bálint, Z., Tamáska, I., Deparis, O., Vigneron, J., and Biró, L., "Photonic band gap materials in butterfly scales: A possible source of blueprints," Materials Science and Engineering: B 149, 259-265 (Apr. 2008).

79. T. Germer, Polarized Light Scattering C++ Class Library. http://pml.nist.gov/Scatmech/html/index.htm (2015).

80. Aspnes, D. E., Theeten, J. B., and Hottier, F., "Investigation of effective-medium models of microscopic surface roughness by spectroscopic ellipsometry," Phys. Rev. B 20, 3292 (1979).

81. Aspnes, D. E. and Theeten, J. B., "Spectroscopic analysis of the interface between si and its thermally grown oxide," J. Electrochem. Soc. 127, 1359 (1980).

82. Petrik, P., Lohner, T., Fried, M., Gyulai, J., Boell, U., Berger, R., and Lehnert, W., "Ellipsometric study of the polysilicon/thin oxide/single-crystalline silicon structure and its change upon annealing," Journal of Applied Physics 92, 2374 (2002).

83. Petrik, P., Szilágyi, E., Lohner, T., Battistig, G., Fried, M., Dobrik, G., and Biró, L. P., "Optical models for ultrathin oxides on Si- and C-terminated faces of thermally oxidized SiC," Journal of Applied Physics 106, 123506 (2009).

84. Franta, D., Ohlídal, I., and Necas, D., "Optical quantities of rough films calculated by Rayleigh-Rice theory," physica status solidi (c) 5, 1395-1398 (May 2008).

85. Aspnes, D. E., "Optical properties of thin films," Thin Solid Films 89, 249 (1982).

86. Liu, Q., Wall, J. F., and Irene, E. A., "Interface studies by spectroscopic immersion ellipsometry and atomic force microscopy," J. Vac. Sci. Technol. A A12, 2625 (1994). 
87. Petrik, P., Biró, L. P., Fried, M., Lohner, T., Berger, R., Schneider, C., Gyulai, J., and Ryssel, H., "Surface roughness measurement on polysilicon produced by low pressure chemical vapor deposition using spectroscopic ellipsometry and atomic force microscopy," Thin Solid Films 315, 186 (1998).

88. Strein, E. and Allred, D., "Eliminating carbon contamination on oxidized Si surfaces using a VUV excimer lamp," Thin Solid Films 517, 1011 (2008).

89. Nutsch, A., Beckhoff, B., Altmann, R., Van den Berg, J., Giubertoni, D., Hoenicke, P., Bersani, M., Leibold, A., Meirer, F., Müller, M., Pepponi, G., Otto, M., Petrik, P., Reading, M., Pfitzner, L., and Ryssel, H., "Complementary Metrology within a European Joint Laboratory," Solid State Phenomena 145-146, 97-100 (2009).

90. van den Berg, J. A., Reading, M. A., Parisini, A., Kolbe, M., Beckhoff, B., Ladas, S., Fried, M., Petrik, P., Bailey, P., Noakes, T., Conard, T., and Gendt, S. D., "High Resolution Depth Profile Analysis of Ultra Thin High-k Hf Based Films Using MEIS Compared with XTEM, XRF, SE and XPS," ECS Transactions 25, 349 (2009).

91. Petrik, P., Lohner, T., Fried, M., Khánh, N. Q., Polgár, O., and Gyulai, J., "Comparative study of ion implantation caused damage depth profiles in polycrystalline and single crystalline silicon studied by spectroscopic ellipsometry and rutherford backscattering spectrometry," Nuclear Instruments and Methods B B147, 84 (1999).

92. Petrik, P., Polgár, O., Fried, M., Lohner, T., Khánh, N. Q., and Gyulai, J., "Ellipsometric characterization of damage profiles using an advanced model," Journal of Applied Physics 93, 1987 (2003).

93. Giubertoni, D., Pepponi, G., Beckhoff, B., Hoenicke, P., Gennaro, S., Meirer, F., Ingerle, D., Steinhauser, G., Fried, M., Petrik, P., Parisini, A., Reading, M. A., Streli, C., van den Berg, J. A., Bersani, M., Secula, E. M., Seiler, D. G., Khosla, R. P., Herr, D., Michael Garner, C., McDonald, R., and Diebold, A. C., "Multitechnique characterization of arsenic ultra shallow junctions in silicon within the ANNA consortium," in [AIP Conference Proceedings], 1173, 45-49, AIP (2009).

94. Mohacsi, I., Petrik, P., Fried, M., Lohner, T., Van Den Berg, J. a., Reading, M. a., Giubertoni, D., Barozzi, M., and Parisini, a., "Characterisation of ultra-shallow disorder profiles and dielectric functions in ion implanted Si," Thin Solid Films 519, 2847-2851 (Feb. 2011).

95. Szilágyi, E., Petrik, P., Lohner, T., Koós, A. A., Fried, M., and Battistig, G., "Oxidation of sic investigated by ellipsometry and rutherford backscattering spectrometry," Journal of Applied Physics 104, 014903 (2008).

96. Fodor, B., Cayrel, F., Agocs, E., Alquier, D., Fried, M., and Petrik, P., "Characterization of in-depth cavity distribution after thermal annealing of helium-implanted silicon and gallium nitride," Thin Solid Films 571, 567-572 (2014).

97. Fried, M., Lohner, T., Jároli, E., Hajdu, C., and Gyulai, J., "Non-destructive determination of damage depth profiles in ion-implanted semiconductors by multiple-angle-of-incidence single-wavelength ellipsometry," Nucl. Instr. Meth. B 55, 257 (1991).

98. Fried, M., Lohner, T., Aarnink, W. A. M., Hanekamp, L. J., and van Silfhout, A., "Nondestructive determination of damage depth profiles in ion-implanted semiconductors by spectroscopic ellipsometry using different optical models," Journal of Applied Physics 71, 2835 (1992).

99. Petrik, P., Agocs, E., Volk, J., Lukacs, I., Fodor, B., Kozma, P., Lohner, T., Oh, S., Wakayama, Y., Nagata, T., and Fried, M., "Resolving lateral and vertical structures by ellipsometry using wavelength range scan," Thin Solid Films 571, 579 (2014). 